\title{
On Persistency of Endowment Effect—Relationship Between Affection and Endowment Effect
}

\author{
Atsuo Murata \\ Okayama University, Okayama, Japan
}

\begin{abstract}
The manager fall into the trap that the older production equipment can still operate safely and with moderate efficiency due to the endowment effect attached to the older production equipment. Such a circumstance where an economic thinking (efficiency) penetrates our decision on equipment replacement hinders rational judgment on the replacement of older equipment from the viewpoint of industrial safety. This must be corresponding to one of the cognitive biases. On the basis of the loss aversion property derived from prospect theory, we discussed whether stronger endowment effect was observed when the affection was attached to the object than when the affection was not attached to the object at all. Stronger endowment effect was observed when the affection was attached to the object than when the affection was not attached to the object at all.
\end{abstract}

Keywords: prospect theory, cognitive bias, loss aversion, endowment effect, affection, adherence to accustomed items

\section{Introduction}

The endowment effect is related to loss aversion which means that we are willing to sacrifice some gains in order to avoid possible loss. We tend to show a preference for what we currently have or be endowed with, even if such an act doesn't necessarily yield higher levels of material welfare. We value our asset by more than its purchase price even if its market value at present is not so high. For each individual who owns an asset, possession itself increases the value of the asset, and the endowment effect arises. The satisfaction accompanied by the endowment effect comes not from economic but from psychological reasons.

We value an item more after we possess it. After we purchase some item for $\$ 100$, we value it more than $\$ 100$. Our level of utility obtained from some item changes by possession of it and over time. If we give up owning some item, we feel the pain of loss. Thus, we often ask a price in excess of the purchase price to sell this item.

The endowment effect can also be interpreted as follows. A lot of experiments have demonstrated that we are generally willing to sell our owned item at a substantially higher price than what we originally paid for the item. Economically, the value of the owned item generally decreases over time. Thus, the endowment effect is regarded as coming from psychological reasons. Our cognition to the owned item is distorted due to such a psychological effect.

The persistency of the endowment effect is argued by many studies. Although the endowment effect arises in a one-shot experiment conducted for naïve participants, experience in a market setting reduces the effect

Atsuo Murata, Professor, Department of Intelligent Mechanical Systems, Graduate School of Natural Science and Technology, Okayama University. 
(Coursey, Hovis, \& Schulze, 1987). On the other hand, Kahneman, Knetsch, and Thaler (1990) found that the endowment effect persisted for advanced graduate students participated in a series of markets. List (2004) examined the willingness to trade coffee mugs and luxury candy bars of a similar financial value for a population gathered at a sports card show, and found that a reluctance to trade one's endowment was common among non-dealers, whereas no such tendency was observed among sports card dealers.

The discussion might deny the persistency of endowment effect, and suggest the possibility that affection is related to the occurrence of endowment effect. The fear of regret might also be included in endowment effect. Thus, the controversy on the persistency of the endowment effect might be mediated by the attachment of affection to the items.

The endowment effect should not be observed for sellers of a variety of products or CEOs of major corporations, because it is unlikely that they would stay in business for long if they feel affectionate toward their products or stocks and display loss aversive tendency. From economic viewpoints, they must mark up prices on the basis of not loss aversion but profit targets. In such a way, the endowment effect is rarely observed in economic world or marketplaces. The endowment effect has a psychological meaning and should be limited to the psychological and irrational situations. Irrational stands for the cases where economic principles are not necessarily applicable and psychological feelings are dominant.

For example, the manager of a factory must always bear in mind to replace older production equipments. Although the managers recognize that it is desirable to replace older production equipments, it is possible that the endowment effect frequently functions under such a situation especially when the replacement costs much and the older production equipment continues operating under a normal and stationary situation. The managers fall into the trap that the older production equipment can still operate safely and with moderate efficiency due to the endowment effect attached to the older production equipment. Such a circumstance where an economic thinking (efficiency) barges into our decision on equipment replacement disables us from reaching the rational and appropriate judgment on the replacement of older equipment from the viewpoint of industrial safety. This must correspond to one of the cognitive biases (Murata \& Nakamura, 2014). As mentioned, our point of view was that endowment effect is not persistent and affection is strongly related to the occurrence of endowment effect.

Therefore, it is important to explore how the endowment effect arises. On the basis of the loss aversion property derived from prospect theory, we discussed whether stronger endowment effect was observed when the affection was attached to the object than when the affection was not attached to the object at all. Some implications related to the safety management were given from the viewpoint of the endowment effect.

\section{Method}

\section{Participants}

All participants with the participation in the questionnaire survey after receiving a brief explanation on the questionnaire. For the condition (A) no affection attachment condition, 21 graduate or undergraduate students from 22 to 24 years old took part in the experiment. Seven participants were allocated to each of (A)-1, (A)-2, and (A)-3 conditions below. For the condition (B) affection attachment condition, graduate or undergraduate students from 22 to 24 years old took part in the experiment. Eighteen, fourteen, and sixteen participants were allocated to (B)-1, (B)-2, and (B)-3 conditions below, respectively. 


\section{Task, Design, and Procedure}

First, the endowment effect is briefly reviewed. We often demand much more to give up and sell an object than we would be willing to pay to acquire it. This pattern is called endowment effect. For example, after we gain possession of a pen by paying $\backslash 10,000$, we would typically want more than $\backslash 10,000$ - say, $\backslash 12,000$ to sell the pen. The endowment effect can also interpreted as a preference for the current state that biases us against both selling and buying, and related to loss aversion-The disutility of giving up and selling an object is greater than the utility associated with acquiring it.

Using the two conditions (A) and (B) below, it was explored how the attachment of affection to the object affected the endowment effect.

(A) no affection attachment condition (no affection is attached to an object)

(A)-1: The participant allocated to this condition was required to image that he or she won the product (ROLEX wrist watch) in a prize. The task is to describe the price at which he or she can sell the product. In the condition (A)-1, the participant was required not to attach affection to the product (object).

(A)-2: The participant was required to describe the price at which he or she can purchase the product.

(A)-3: The participant was required to select the price from the range $(10,000-13,000,000)$ which he or she wanted to own the product if the purchase price is less than the presented price.

(B) affection attachment condition (affection is attached to an object)

(B)-1: The task is to describe the price at which he or she can sell the product. In the condition (B)-1, the participant was required to attach affect to the product (SEIKO King Quarts wrist watch). In other words, the participant was required to image that he or she liked the product and use habitually.

(B)-2: The participant was required to describe the price at which he or she can purchase the product.

(B)-3: The participant was required to select the price from the range $(\backslash 10,000-1400,000)$ which he or she wanted to own the product if the purchase price is less than the presented price.

\section{Results and Discussion}

In Figure 1, the mean price is compared among (A)-1, (A)-2, and (A)-3. In Figure 2, the mean price is compared among (B)-1, (B)-2, and (B)-3. As a result of a one-way (Condition (A)-1, (A)-2, and (A)-3) conducted on the price, no significant main effect was detected. A multiple comparison by Fisher's PLSD (Protected Least Significance Difference) revealed no significant differences. A similar one-way ANOVA conducted on the price of the condition (B) revealed no significant main effect. Fisher's PLSD revealed the following differences: (B)-1 and (B)-2, and (B)-1 and (B)-3.

As shown in Figure 1, the mean price between (A)-1 and (A)-2 did not differ. Moreover, the mean price of (A)-3 was by far larger than that of (A)-1 and (A)-2. These results mean that the endowment effect is not necessarily observed. In Figure 2, the mean price of (B)-1 was significantly higher than that of (B)-2, and (B)-3, which means that the endowment effect was observed. The difference between Figure 1 and Figure 2 must indicate that endowment effect does not occur universally, and is not persistent as pointed out by Kahneman, Knetsch, and Thaler (1990).

As mentioned above, the endowment effect is a preference for the current state that biases us against both selling and buying, and is related to loss aversion. The attachment of affection to an object may be prerequisite for producing loss aversive feeling and eventually endowment effect. Such a cognitive bias leads to the persistence of some idea or strategy, which eventually induces a bias of decision making. Therefore, the 
endowment effect should be fully taken into account in risk management.

For example, the manager of a factory must always bear in mind to replace older production equipments. Although the manager thoroughly recognize that it is desirable to replace older production equipments for the sake of safety, it is possible that the endowment effect frequently functions under such a situation especially when the replacement costs much and the older production equipment continues operating normally under a stationary situation. In such a situation, it is possible that the manager falls into the trap of cognitive bias that the older production equipment can still operate safely and with moderate efficiency due to the endowment effect attached to the older production equipments. If the manager pays emphasis on the efficiency rather than the safety, this leads to irrational decision on equipment replacement to continue to use old equipments with a potential risk of crucial accident without viewing the replacement from the viewpoint of industrial safety. This must be corresponding to one of the cognitive biases (Murata \& Nakamura, 2014).

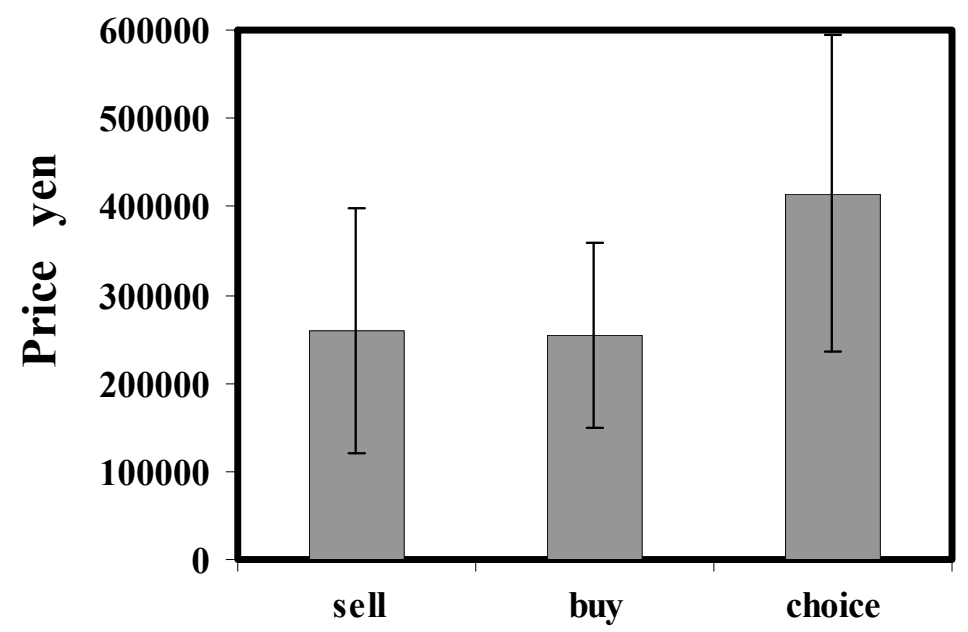

Figure 1. Reported price compared among (A)-1 (sell), (A)-2 (buy), and (A)-3 (choice).

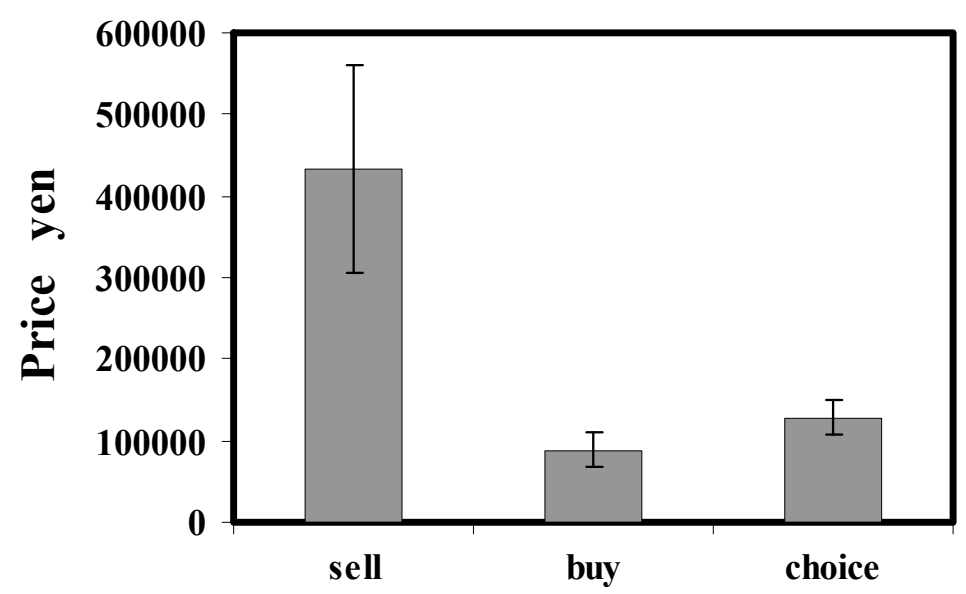

Figure 2. Reported price compared among (B)-1 (sell), (B)-2 (buy), and (B)-3 (choice).

In Fukushima Daiichi nuclear power plant accident occurred on March in 2011 (Ladkin, Goeker, \& Sieker, 2013; Hirose, 2011; Hindmarsh, 2013), the reactor \#1 had been operating for about 40 years. The reactor \#1 
began operating on March in 1973. It is generally accepted that the reactor should not be used for more than 40 years, although this is not prescribed by laws and regulations. TEPCO (Tokyo Electric Power Company) must have certainly recognized the necessity of the reactor \#1 to decommission. However, they must have fallen into the trap of the endowment effect, and have affectively concluded that their older reactor \#1 can be kept using for further 10 years. This is one of the causes of Fukushima Daiichi nuclear power plant accident. The reactors \#5 and \#6 were the latest ones, and the damage by Tsunami and earthquake was less severe. In such a way, it is possible that the cognitive bias induced by the endowment effect becomes a potential risk factor of crucial accidents.

\section{Conclusions}

On the basis of the loss aversion property derived from prospect theory, we discussed the endowment effect. Stronger endowment effect was observed when the affection was attached to the object than when the affection was not attached to the object at all.

Future research should discuss how the finding on the endowment effect when strong affection was attached to the items should be effectively made use of to prevent violation-based crucial accident such Fukushima Daiichi nuclear power plant accident as mentioned above from occurring.

\section{References}

Coursey, D. L., Hovis, J. L., \& Schluze, W. D. (1987). The disparity between willingness to accept and willingness to pay measures of value. The Quarterly Journal of Economics, 102, 679-690.

Hindmarsh, R. (2013). Nuclear disaster at fukushima daiichi-Social, political and environmental issues. Routledge.

Hirose, T. (2011). Fukushima meltdown-The world's first earthquake-Tsunami-Nuclear Disaster. Ashi Shinsho Book.

Kahneman, D., Knetsch, J. L., \& Thaler, R. (1990). Experimental tests of the endowment effect and he Coase theorem. Journal of Politic Economy, 98, 1325-1348.

Ladkin, P. B., Goeker, C., \& Sieker, B. (2013). The Fukushima Dai-Ichi Accident. LIT, Berlin.

List, J. A. (2004). Neoclassical theory versus prospect theory: Evidence from the marketplace. Econometrica, 72(2), 615-625.

Murata, A., \& Nakamura, T. (2014). Basic study on prevention of human error-How cognitive biases distort decision making and lead to crucial accidents. Proc. of AHFE2014, 136-141. 